\title{
Correction
}

\section{Correction to: Thermally-Induced Failure of Smoke Alarms}

Geraldine Martin, Haavard Boehmer and Stephen M. Olenick* (D), Combustion

Science and Engineering, Inc., 8940 Old Annapolis Road, Suite L,

Columbia, MD 21045, USA

Geraldine Martin, Olsson Fire and Risk, Auckland, New Zealand

\section{Correction to: Fire Technology https://doi.org/10.1007/s1 0694-019-00898-6}

The original version of this article unfortunately contained an error in the Acknowledgement section.

The authors' details were made blinded during the manuscript review process, and the article was published as such with the word "BLIND" in place of the authors' information.

The correct complete acknowledgement is as follows:

This work was funded internally by Combustion Science \& Engineering, Inc. The authors thank Maclain Holton for his assistance with the sound measurement equipment and Brent Turner for his assistance with design and construction of the heating tunnel apparatus. The authors also thank Dr. Michael Klassen for his constructive comments on the experiments, analysis, and paper.

* Correspondence should be addressed to: Stephen M. Olenick, E-mail: solenick@csefire.com

The original article can be found online at https://doi.org/10.1007/s10694-019-00898-6. 